\title{
Defective Respiratory Capacity and Mitochondrial Protein Synthesis in Transformant Cybrids Harboring the tRNA Leu(UUR) Mutation Associated with Maternally Inherited Myopathy and Cardiomyopathy
}

\author{
Caterina Mariotti, * Valeria Tiranti, * Franco Carrara, * Bruno Dallapiccola, ${ }^{\star}$ Stefano DiDonato, * and Massimo Zeviani \\ ${ }^{*}$ Istituto Neurologico C. Besta, Department of Biochemistry and Genetics, 20133 Milano, Italy; and ${ }^{\star}$ Istituto Casa Sollievo della \\ Sofferenza, Laboratory of Genetics, 410215 San Giovanni Rotondo, Italy
}

\begin{abstract}
We studied the physiometabolic effects of a mitochondrial DNA (mtDNA) heteroplasmic point mutation, the $A \rightarrow G^{3260}$ transition associated with maternally inherited myopathy and cardiomyopathy. To eliminate the possible influence of the autochthonous nuclear gene set, we fused myoblast-derived cytoplasts of a patient with a human tumoral cell line deprived of mtDNA $\left(\right.$ Rho $\left.^{\circ}\right)$. The presence and amount of the mutant $G^{3260}$ vs the wild-type $A^{3260}$ were measured by solid phase minisequencing. We observed a marked reduction of the percentage of mutant mtDNA in the culture system compared with that measured in the donor's muscle biopsy, suggesting the presence of negative selection against the mutation. Furthermore, stable mitotic segregation of the two mtDNA populations was observed in 18 of 19 transformant clones, suggesting the presence of intraorganelle and possibly intracellular homoplasmy in the precursor cells of the donor. Several indexes of mtDNA-related respiratory capacity, including oxygen consumption, complex I- and complex IV-specific activities, and lactate production, were markedly abnormal in the clones containing a high proportion of mutant mtDNA, as compared with those containing homoplasmic wild-type mtDNA, possibly because of impaired mitochondrial protein synthesis. We conclude that $(a)$ the $A \rightarrow$ $G^{3260}$ transition is indeed responsible for the mitochondrial disorder identified in the donor patient, and (b) transformant cybrid system gives direct evidence of the mitochondrial origin of a genetic disorder and should be adopted for the evaluation of the pathogenic potential of the mtDNA mutations. (J. Clin. Invest. 1994. 93:1102-1107.) Key words: mitochondrial DNA• rho $^{\circ} \cdot$ respiratory chain $\cdot$ ragged-red fibers $\bullet$ heteroplasmy
\end{abstract}

\section{Introduction}

We have recently described a maternally inherited adult-onset syndrome, characterized clinically by the variable combination

Address correspondence to Dr. Massimo Zeviani, Department of Biochemistry and Genetics, Istituto Nazionale Neurologico C. Besta, via Celoria 11, Milano, Italy I-20133.

Received for publication 6 August 1993 and in revised form 22 October 1993.

J. Clin. Invest.

(c) The American Society for Clinical Investigation, Inc.

0021-9738/94/03/1102/06 \$2.00

Volume 93, March 1994, 1102-1107 of skeletal and heart muscle failure (MIMyCa, ${ }^{1}$ maternally inherited myopathy and cardiomyopathy), and molecularly by the presence of a heteroplasmic point mutation in mitochondrial DNA (mtDNA) transfer RNA (tRNA) ${ }^{\text {Leu(UUR) }}$ gene (1). The pathogenicity of the mutation, an $A \rightarrow G$ transition at mtDNA nucleotide position 3260 (2), was based on the following evidence: $(a)$ the mutation affected a highly conserved nucleotide and disrupted an A-T pair in the proposed anticodon stem of the tRNA secondary structure, presumably perturbing the stability of the tRNA ${ }^{\text {Leu(UUR) }}$ cloverleaf; $(b)$ the mutation segregated specifically with the disorder; and $(c)$ there were significant correlations between the proportion of the mtDNA that was of the mutant form and the activities (normalized for citrate synthase activity) of two mtDNA-dependent respiratory enzymes (i.e., complex I and complex IV) and the maximum oxygen consumption, a physiologic index of aerobic metabolism.

However, the relevance of this mutation for the pathogenesis of MIMyCa could still be questioned, since: $(a)$ it was reported in a single family; $(b)$ the method used for quantitation of the proportions of the two populations of mtDNA, based on densitometry of PCR products, was rather inaccurate; $(c)$ a possible influence of autochthonous nuclear gene products could not be excluded, since biochemical and molecular analysis was performed on patients' muscle biopsies, and the physiometabolic investigations (i.e., measurement of maximal oxygen consumption ) were carried out in vivo; and $(d)$ similar to other point mutations in tRNA genes, the $A \rightarrow G^{3260}$ transition was proposed to affect the mitochondrial oxidative phosphorylation (OXPHOS) by compromising the ability of mitochondria to translate their own genes. However, no direct demonstration of the effects on mitochondrial translation was offered since a suitable ex vivo system was not available at that time.

To answer these objections and to study the effects of the $\mathrm{G}^{3260}$ mutation in a fully controlled ex vivo system, we prepared transformant cybrid clones $(3)$ by fusing cytoplasts derived from a $\mathrm{G}^{3260}$-positive patient with tumor cells deprived of mtDNA ( rho ${ }^{\circ}$ cells). The relative amount of the mutant $\mathrm{G}^{\mathbf{3 2 6 0}}$ was measured using solid phase minisequencing (SPMS), a suitable method for accurate quantification of mtDNA point

1. Abbreviations used in this paper: $\mathrm{BrdU}, 5$-bromodeoxyuridine; $\mathrm{CO}$ cytochrome $c$ oxidase; I, intermediate; M, mutant; MERRF, myoclonic epilepsy and ragged-red fibers; MIMyCa, maternally inherited myopathy and cardiomyopathy; mtDNA, mitochondrial DNA; ND, NADH-CoQ reductase; nt, nucleotide; OXPHOS, oxidative phosphorylation; rho ${ }^{\circ}$ cells, tumor cells deprived of mtDNA; SPMS, solid phase minisequencing; TK, thymidine kinase; WT, wild-type. 
mutations (4). The presence of the mutation was then correlated with several biochemical, metabolic, and molecular-genetic indexes of mitochondrial respiratory capacity. Using this approach, we present here strong evidence that the MIMyCa mutation is indeed the cause of the OXPHOS impairment found in our patients, most likely because of defective translation of mitochondrial polypeptides. As an important corollary, this study shows that transmitochondrial cybrids can be used to verify whether the presence of a given mtDNA mutation is necessary and sufficient to cause a human disease.

\section{Methods}

Patient. The MIMyCa patient was a 23-yr-old man (for details see subject III-1 in reference 1) who suffered from heart failure and muscle weakness due to skeletal myopathy with ragged-red fibers. He had an enlarged liver, bilateral ankle edema, and an enlarged left ventricle. Densitometric quantitation showed that $90 \%$ of mtDNA extracted from skeletal muscle was mutant.

Cell culture. An mtDNA-less cell line was isolated after treatment of human osteosarcoma 143B thymidine kinase-deficient $\left(\mathrm{TK}^{-}\right)$cells (American Type Culture Collection, Rockville, MD) with $50 \mathrm{ng} / \mathrm{ml}$ ethidium bromide for $2 \mathrm{mo}$, as described ( 3 ). $\mathrm{Rho}^{\circ}$ cells were grown in DME containing $4.5 \mathrm{~g} /$ liter glucose and $110 \mu \mathrm{g} / \mathrm{ml}$ pyruvate, supplemented with 5\% FBS (Boehringer Mannheim Corp., Indianapolis, IN), $50 \mu \mathrm{g} / \mathrm{ml}$ uridine, and $100 \mu \mathrm{g} / \mathrm{ml} \mathrm{5-bromodeoxyuridine} \mathrm{(BrdU;}$ Sigma Immunochemicals, St. Louis, MO). Mass myoblast cultures were established from a muscle biopsy of patient III-1 according to Askanas and Engel (5) with minor modifications. Myoblasts were grown in F14 medium (Seromed, Berlin, Germany) containing $6 \mathrm{~g}$ / liter glucose and supplemented with $15 \% \mathrm{FBS}, 10 \mathrm{ng} / \mathrm{ml} \mathrm{EGF}, 50 \mathrm{ng} /$ $\mathrm{ml}$ fibroblast growth factor (FGF), $10 \mu \mathrm{g} / \mathrm{ml}$ insulin, and $50 \mu \mathrm{g} / \mathrm{ml}$ uridine.

To obtain transmitochondrial cybrids, $\sim 2-5 \times 10^{5}$ myoblasts were enucleated by centrifugation in the presence of cytochalasin $B(10$ $\mu \mathrm{g} / \mathrm{ml})$, and then were cocultured and fused with $10^{6}$ rho $^{\circ}$ cells by briefly adding a solution of $50 \%(\mathrm{wt} / \mathrm{vol})$ polyethylene glycol and $10 \%$ DMSO in phosphate buffer. $24 \mathrm{~h}$ after fusion, cybrids were replated and were continuously grown in DME supplemented with 5\% dialyzed FBS and $100 \mu \mathrm{g} / \mathrm{ml} \mathrm{BrdU.} \mathrm{14-16} \mathrm{d} \mathrm{after} \mathrm{fusion,} \mathrm{cybrids} \mathrm{were} \mathrm{plated} \mathrm{at}$ low density for selection of cell clones in the same medium used for the rho ${ }^{\circ}$ cells.

DNA analysis. Total DNA was extracted from the cybrid clones, as described previously (6). RFLP analysis was used to distinguish the mtDNA of the donor cells from that of the parental 143B cells, since an HaeIII restriction site at position 16517 was absent in the former (7) and present in the latter mtDNA.

Characterization of the nuclear DNA was carried out using the highly polymorphic repetitive sequence D1 $1 \mathrm{~S} 533$ present on chromosome $11 \mathrm{q}$ as described (8).

RFLP analysis with XmnI of DNA fragments obtained by mispaired PCR according to Zeviani et al. (1) was routinely used to identify the $\mathrm{G}^{3260}$ mutation. Quantification of the mutation was performed using SPMS (4). Briefly, the mtDNA fragment encompassing nucleotides ( $\mathrm{nt}$ ) 3213-3310 was PCR-amplified from each cell clone DNA. The sense primer, biotinylated at the $5^{\prime}$ end, corresponded to the mtDNA sequence from nt 3213 to 3232; the antisense primer, also serving as a detection primer, corresponded to the reverse-complementary mtDNA sequence from nt 3261 to 3310 . Aliquots $(10 \mu \mathrm{l})$ of the PCR reaction were incubated for $1.5 \mathrm{~h}$ at $37^{\circ} \mathrm{C}$ in microtitration wells precoated with streptavidin (Labsystems, Finland). After denaturation with $50 \mathrm{mM} \mathrm{NaOH}$, two one-step primer extension reactions were carried out directly in the microwells using the antisense primer. In one reaction, to detect the wild-type $A^{3260}$ the radioactive nucleotide species to be incorporated was $0.4 \mu \mathrm{M}\left[{ }^{3} \mathrm{H}\right] \mathrm{dTTP}$; in the second reaction, to detect the mutant $\mathrm{G}^{3260}$ the radioactive nucleotide species was $\left[{ }^{3} \mathrm{H}\right]-$ dCTP.

After washing with $20 \mathrm{mM}$ Na-phosphate buffer $\mathrm{pH} 7.5$, and $0.1 \%$ Tween 20, the radiolabeled DNA products of the primer extension reactions were eluted with $50 \mathrm{mM} \mathrm{NaOH}$. Radioactivity was measured in a liquid scintillation counter and the $\left[{ }^{3} \mathrm{H}\right] \mathrm{C} /\left[{ }^{3} \mathrm{H}\right] \mathrm{T}$ ratios were compared with a standard curve obtained by using known proportions of the mutant and wild-type mtDNA fragments as templates for the PCR reactions.

Analysis of the mitochondrial translation products. Samples of $\approx 0.5 \times 10^{6}$ cells were labeled with $\left[{ }^{35} \mathrm{~S}\right]$ methionine $(>1,000 \mathrm{Ci} /$ $\mathrm{mmol}, 125 \mu \mathrm{Ci} / \mathrm{ml}$ ) for 30 and $60 \mathrm{~min}$ in $2 \mathrm{ml}$ methionine-free DME supplemented with $50 \mu \mathrm{g} / \mathrm{ml}$ uridine, $100 \mu \mathrm{g} / \mathrm{ml}$ emetine, and $5 \%$ dialyzed FBS as described by Chomyn et al. (9). Equal amounts $(50 \mu \mathrm{g})$ of total cellular protein measured by the method of Lowry et al. ( 10$)$ were electrophoresed through a $15 \%$ SDS Laemmli polyacrylamide gel (11), and the mitochondrial translation products were visualized by fluorography on Kodak X-Omat AR films. Assignment of the mitochondrial translation products was based on similarity of the labeling pattern to that described elsewhere $(7,9)$. Quantitative densitometry was performed with a video copy processor (model P68E; Mitsubishi, Tokyo, Japan ), a contour synthesizer (IV-530; FOR-A Co. Limited, France), and the Bio-Profil software package (Vilber Lourmat, Marne-La-Vallee, France).

Biochemical assays. Oxygen consumption by intact cells was measured with an oxygraph (Hansatech, UK) on samples of $10^{6}-4 \times 10^{6}$ cells in $300 \mu$ l of DME lacking glucose (9).

Rotenone-sensitive NADH-CoQ reductase-(ND, complex I) and cytochrome $c$ oxidase-(CO, complex IV) specific activities were measured in duplicate on cell homogenates after $2 \times$ sonication for $3 \mathrm{~s}$, as described previously (12).

To measure the lactic acid production, $5 \times 10^{5}$ cells of each clone were plated on $60-\mathrm{mm}$ petri dishes and were incubated in $2 \mathrm{ml} \mathrm{RPMI-}$ 1640 lacking phenol red and supplemented with $2 \mathrm{~g}$ /liter glucose, 50 $\mu \mathrm{g} / \mathrm{ml}$ uridine, $4 \% \mathrm{FBS}$, and $2 \mathrm{mM}$ glutamine. After incubation for 48 $\mathrm{h}$, lactic acid concentration was measured in the culture medium according to Noll (13), and lactic acid production was expressed as micromoles per milligram of total cell protein.

Statistics. Statistical significance was calculated using the unpaired two-tailed Student's $t$ test.

\section{Results}

Production of transmitochondrial cybrids. We collected 19 transformant cybrid clones (identified by the letter $\mathbf{P}$ for patient III-1) after fusion of rho ${ }^{\circ}$ cells derived from the $143 \mathrm{BTK}^{-}$ cell line with cytoplasts obtained by enucleation of myoblasts of MIMyCa patient III-1. After polyethylene glycol fusion, selection was carried out by using a culture medium lacking pyrimidines and containing BrdU. Rho $^{\circ}$ cells are TK deficient and auxotrophic for pyrimidines because of the lack of a functional respiratory chain (3). Therefore, only the rho ${ }^{\circ}$ cells that had fused with cytoplasts could survive in this medium, while the rho ${ }^{\circ}$ cells that had not fused or that had fused with residual intact fibroblasts or myoblasts, as well as any residual intact fibroblasts or myoblasts, were eliminated. We used a culture of rho ${ }^{\circ}$ cells as a control for selection. After $15 \mathrm{~d}$ of selection, when the rho ${ }^{\circ}$ cells used as controls had all died, we added uridine to the medium to eliminate any growth disadvantage of cells containing mutations affecting mitochondrial function, which is required for uridine-independent growth. Selection with BrdU against expression of the $\mathrm{TK}^{+}$phenotype was maintained during the entire culture period.

As a prerequisite for further investigation, we first con- 

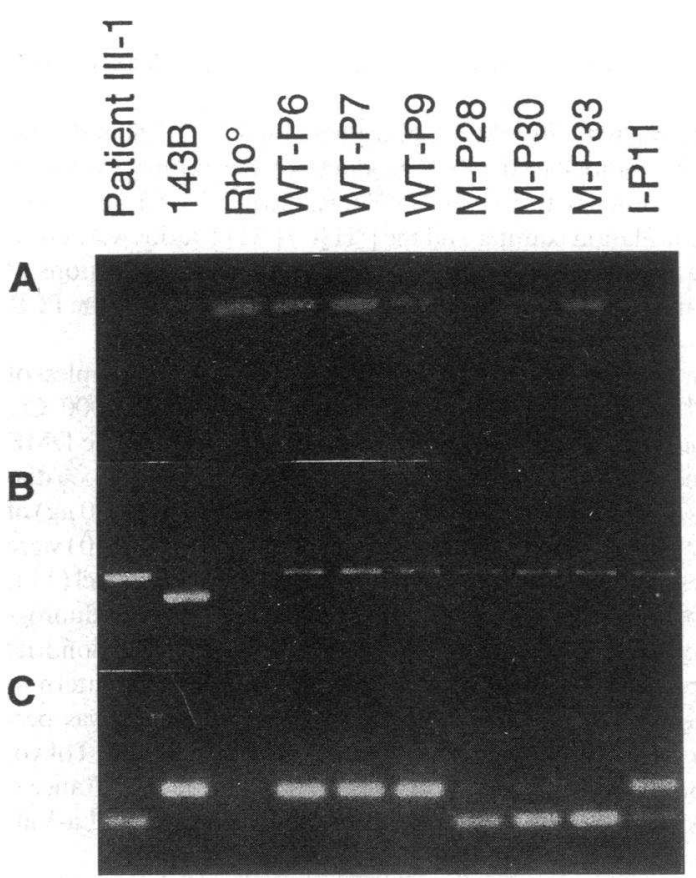

Figure 1. Genetic characterization of donor, parent, and transformant cybrid cells. $(A)$ PCR amplification of the D1 1S533 locus. Amplification of the nuclear DNA of the donor patient III- 1 produces a twoband pattern ( $\sim 530$ and $450 \mathrm{bp}$ ), which differs from the single band obtained from the nuclear DNA of the other cell lines, including 143B cells, the rho ${ }^{\circ}$ cells, three WT and three $M$ transformant cybrid clones, as well as the only cybrid clone with intermediate levels of mutation. Samples of DNA from the cybrid clones are indicated according to the nomenclature of Table I. $(B)$ HaeIII RFLP analysis. Digestion with HaeIII of PCR fragments encompassing the mtDNA region from nt 16460 to 300 . An extra HaeIII site at nt position 16517 distinguishes the mtDNA of 143B from that of the patient and that of the transformant cybrids. No PCR fragment was obtained from the rho ${ }^{\circ}$ cells. $(C) \mathrm{XmnI}$ RFLP analysis of the presence and quantity of the $\mathrm{G}^{3260} \mathrm{mtDNA}$ mutation, using digestion with $\mathrm{XmnI}$. A diagnostic XmnI site was created in the presence of the mutant $G^{3260}$ by mispaired PCR, according to Zeviani et al. (1). The smaller DNA fragments ( $126 \mathrm{bp}$ long) are cleavage products of the XmnI digestion of PCR fragments containing the mutant $\mathrm{G}^{3260}$; the longer DNA fragments (166 nt long) are the uncleaved PCR products containing the wild-type $A^{3260}$. No PCR fragment was obtained from the rho ${ }^{\circ}$ cells.

firmed the presence of normal amounts of mtDNA in each clone by Southern blot analysis (not shown).

Each clone was then examined to verify that the mitochondrial genotype was identical to the donor myoblasts and fibroblasts and that the nuclear genotype was identical to that of the nuclear parent, the 143B cell line (Fig. 1). For the mitochondrial genotype, we verified the absence of an HaeIII RFLP reported in the original mtDNA of the $143 \mathrm{~B}$ cell clone and absent in the mtDNA of MIMyCa patient III-1. For the nuclear genotype, we demonstrated that the DNA of all the cybrid clones were homozygous for the same length polymorphism at the D1 1S533 locus of their nuclear parent, 143B, which differed from the heterozygous pattern found in the donor patient.

SPMS was used to measure the percentage of the mutant $\mathrm{G}^{3260}$ and the wild-type $\mathrm{A}^{3260}$ ( Table I). The percentage of mutation in the massive transformant culture after selection with uridine-less medium was $56 \%$ of the total. SPMS quantitation in single cell clones revealed that 10 of $19(53 \%)$ of the clones contained $>90 \%$ mutant mtDNA (M clones), 8 of $19(42 \%)$ were homoplasmic wild-type (WT clones), and only $1(5 \%)$ had intermediate levels of mutant and wild-type mtDNA (40\% $\mathrm{A}^{3260} ; 60 \% \mathrm{G}^{3260}$; I clone).

The percentages of mutation in each clone, including the I clone, were reexamined by SPMS after 4-8 wk of continuous culture. No variation from the first measurement was observed.

Mitochondrial DNA translation. Several M clones and WT clones were tested for mitochondrial protein synthesis.

Fig. 2 shows the results of two representative experiments carried out on two M clones (P28 and P8) and two WT clones ( $\mathrm{P} 9$ and $\mathrm{P} 26$ ). Incorporation of $\left[{ }^{35} \mathrm{~S}\right]$ methionine in the presence of emetine, an inhibitor of cytoplasmic protein synthesis, was allowed to proceed for either 30 or $60 \mathrm{~min}$.

The qualitative patterns of mitochondrial translation products were virtually identical in the four clones, irrespective of the presence of the mutation. This result differs from that reported for the mitochondrial encephalomyopathy lactic acidosis and strokelike episodes $\mathrm{G}^{3243}$ mutation, in which a slight increase in the electrophoretic mobility of ND1 was observed (7), as well as for the myoclonic epilepsy and ragged-red fibers (MERRF) $\mathrm{G}^{8343}$ mutation, in which a prominent extra band was observed running immediately below ND4 (9).

From a quantitative standpoint, the $\mathrm{M}$ clone $\mathrm{P} 28$ showed a generalized decrease in the incorporation of $\left[{ }^{35} \mathrm{~S}\right]$ methionine into the mitochondrial-encoded polypeptides. The decrease was more evident after labeling of cells for $30 \mathrm{~min}$ ( $40 \%$ of the mean between the average profile of WT clones P9 and P26) than after labeling for $60 \mathrm{~min}(70 \%)$. By contrast, the labeling of $\mathrm{M}$ clone $\mathrm{P} 8$ was only slightly decreased compared with that of the WT clones ( 85 and $80 \%$ at 30 and $60 \mathrm{~min}$, respectively).

Mutation segregates with biochemical defects of the respiratory chain. We investigated the respiratory capacity of the cell clones by measuring the specific activities of two respiratory chain complexes, both containing mtDNA-encoded subunits (seven in complex I and three in complex IV), and the rate of oxygen consumption in intact cells. We did not normalize the respiratory chain activities for citrate synthase, because citrate synthase is also expressed at high levels in the rho ${ }^{\circ}$ mitochondria of the host cells. In six M clones and six WT clones, we also measured the concentration of lactic acid released in the culture medium at $48 \mathrm{~h}$ after plating.

As shown in Table I, results were significantly different between the $\mathrm{M}$ and the WT groups, clearly indicating defective respiration in the former compared with the latter. In particular, the mean value for oxygen consumption in the $\mathbf{M}$ group was $41 \%$ of the mean of the WT group $(P<0.0001)$; the mean value for lactic acid production in the $M$ group was $218 \%$ of that of the WT group $(P<0.0001)$. The mean of the complex I activities in the M group was $63 \%$ of that in the WT group ( $P$ $<0.0001)$; the mean of the complex IV activities was $67 \%(P$ $<0.0005)$. The values for oxygen consumption and complex I and complex IV activities did not vary significantly between the WT group and the mean obtained from five cybrid clones derived from myoblasts of a normal subject (control group in Table I). Lactate production was not measured in this group. In the only clone (P11) with an intermediate amount of mutation, we measured only the oxygen consumption and found it similar to that of WT clones, suggesting that for the $\mathrm{G}^{\mathbf{3 2 6 0}} \mathrm{mu}$ tation the threshold for detectable impairment of mitochondrial respiration is higher than $60 \%$ mutant mtDNA ( Table I). 
Table I. mtDNA Analysis and Biochemical Results in Transformant Cybrids

\begin{tabular}{|c|c|c|c|c|c|c|}
\hline Clone & $\begin{array}{c}\text { Percentage of WT } \\
\text { mtDNA }\end{array}$ & Group & $\mathrm{O}_{2}$ consumption & Complex I & Complex IV & Lactate $48 \mathrm{~h}$ \\
\hline & & & fmol/min per cell & nmol/min per mg & nmol/min per $m g$ & $\mu \mathrm{mol} / \mathrm{mg}$ total protein \\
\hline P2 & 5.5 & $\mathbf{M}$ & 2.4 & 14.6 & 29.9 & 225 \\
\hline P4 & 4.8 & $\mathbf{M}$ & 2.7 & 13.8 & 23.6 & 294 \\
\hline P8 & 8.7 & $\mathbf{M}$ & 1.4 & 12.8 & 25.9 & - \\
\hline P14 & 4.9 & $\mathbf{M}$ & 1.6 & 14.1 & 20.0 & 204 \\
\hline P28 & 2.3 & $\mathbf{M}$ & 1.5 & 12.5 & 23.9 & - \\
\hline P30 & 8.5 & $\mathbf{M}$ & 2.1 & 9.9 & 24.7 & 268 \\
\hline P31 & 4.4 & $\mathbf{M}$ & 1.4 & 14.9 & 19.7 & 226 \\
\hline P33 & 3.9 & $\mathbf{M}$ & 1.6 & 12.0 & 25.4 & - \\
\hline P35 & 4.4 & $\mathbf{M}$ & 1.4 & 10.8 & 18.3 & 268 \\
\hline \multirow[t]{2}{*}{ P39 } & 3.1 & $\mathbf{M}$ & 1.6 & 11.9 & 25.0 & - \\
\hline & & $\overline{\mathrm{X}} \pm \mathrm{SD}$ & $1.8 \pm 0.4$ & $12.7 \pm 1.6$ & $23.6 \pm 3.3$ & $247 \pm 34$ \\
\hline P5 & 100.0 & WT & 4.1 & 21.2 & 35.5 & 115 \\
\hline P6 & 100.0 & WT & 4.6 & 25.1 & 42.8 & 106 \\
\hline P7 & 100.0 & WT & 4.2 & 22.9 & 26.6 & 117 \\
\hline P9 & 99.6 & WT & 5.9 & 13.8 & 31.2 & - \\
\hline P10 & 100.0 & WT & 4.0 & 20.1 & 30.8 & 108 \\
\hline P16 & 99.6 & WT & 3.9 & 23.2 & 37.2 & - \\
\hline P22 & 100.0 & WT & 3.7 & 14.8 & 28.8 & 100 \\
\hline \multirow[t]{2}{*}{ P26 } & 99.6 & WT & 4.1 & 19.8 & 49.5 & 126 \\
\hline & & $\overline{\mathrm{X}} \pm \mathrm{SD}$ & $4.3 \pm 0.7$ & $20.1 \pm 4.0$ & $35.3 \pm 7.7$ & $112 \pm 9.2$ \\
\hline P11 & 40.3 & I & 3.6 & - & - & - \\
\hline Control group $(n=5)$ & & $\overline{\mathrm{X}} \pm \mathrm{SD}$ & $4.84 \pm 0.9$ & $21.5 \pm 5.3$ & $34.9 \pm 13.6$ & - \\
\hline
\end{tabular}

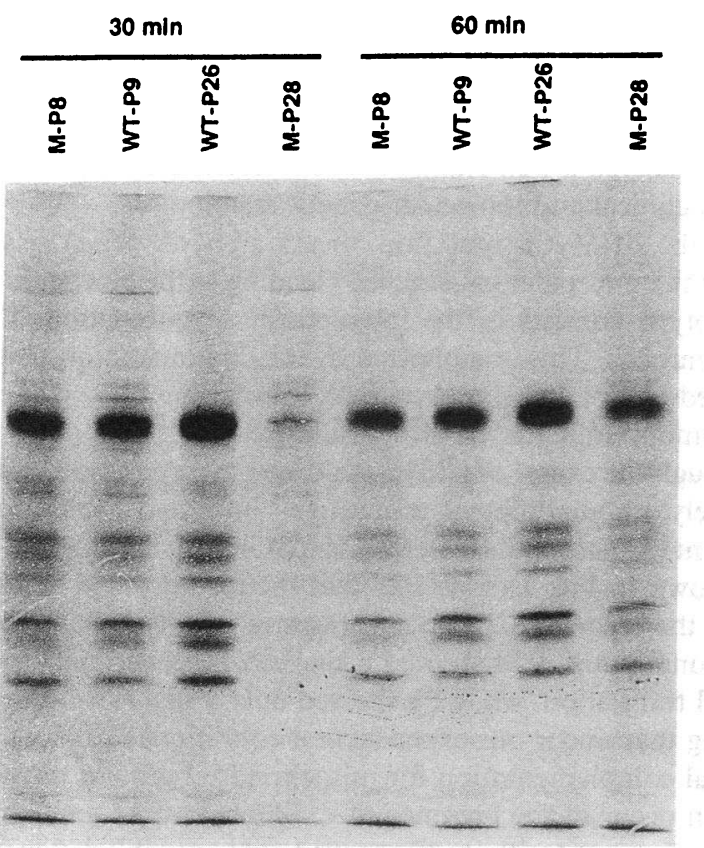

ND5 $\mathrm{COI}$

ND4

Cyt b ND1

coll

ATPase 6

ND6

ND3

Figure 2. Analysis of the mitochondrial translation products in cybrid cell lines with and without the $\mathrm{G}^{3260}$ MIMyCa mutation. Fluorogram of mitochondrial translation products labeled with $\left[{ }^{35} \mathrm{~S}\right]$ methionine in the presence of $100 \mu \mathrm{g} / \mathrm{ml}$ emetine after electrophoresis through a $15 \%$ SDS-polyacrylamide gel. Two sets of experiments were carried out by labeling the same M and WT cybrid clones for 30 or $60 \mathrm{~min}$. Equal amounts of total cellular protein $(50 \mu \mathrm{g})$ were loaded on each lane of the gel. Cybrid clones are indicated according to the nomenclature of Table I. The mitochondrial protein products were identified by comparison with similar experiments shown in references 7,9 , and 12 . Cyt $\mathrm{b}$, cytochrome $b$.
This finding is compatible with the observation that all symptomatic patients in our kindred had a percentage of mutation in muscle of at least $87 \%$, while one unaffected individual had a percentage of mutation as high as $78 \%$ ( 1 ).

\section{Discussion}

Given the high mutation rate and the great intraspecific variability of mtDNA, it is difficult to distinguish between pathogenic and nonpathogenic point mutations. The number of putatively pathogenic mtDNA mutations reported in the scientific journals has steadily increased in the recent past, making a thorough investigation of the normal variability of human mitochondrial genome as necessary as the identification of true or consensus mutations (14-17). There is general agreement that the pathogenicity of a given mtDNA mutation should be based on the following criteria (18): $(a)$ evolutionary conservation and/or obvious functional importance of the mutated nucleotide or amino acid; $(b)$ heteroplasmy; $(c)$ segregation with the disease; and $(d)$ positive correlation between heteroplasmy and severity of the clinical and biochemical phenotype. However, most of the reported mutations do not fulfill all or even the majority of these criteria. For instance, several mutations are homoplasmic, or are also present in the general population, or have been reported only in single individuals. Most importantly, many of them have not been correlated with functional defects. Based on the results of this and other studies, we believe that the demonstration of impaired OXPHOS in a fully controlled system, free of potentially misleading conditions that cannot be avoided in in vivo studies, gives reliable proof of the mtDNA origin of a genetic disorder.

Transmitochondrial cybrids offer several advantages. Since 
all cybrid clones contain the same nuclear genotype of the host rho ${ }^{\circ}$ cell line, mutations in the nuclear genes of the proband are ruled out. Likewise, this system eliminates the influence of the autochthonous nuclear genetic background on the expression of the phenotype associated with the mitochondrial mutation to be tested. In addition, availability of immortal clones containing different amounts of a given mitochondrial mutation makes it possible to study the genotype-phenotype relations in a quantitative way. Finally, cybrid clones containing homoplasmic wild-type mtDNA of the patients can be used as internal controls, eliminating the possibility that changes in the mtDNA other than the tested mutation may influence the expression of the cellular phenotype.

We used transmitochondrial cybrids to confirm and to further characterize the pathogenicity of a heteroplasmic point mutation of mtDNA, the $A \rightarrow G^{3260}$ transition, putatively responsible for the MIMyCa phenotype. To eliminate the intrinsic inaccuracy of densitometric measurement, SPMS was used as a highly reliable method to quantitate the amount of mutation. This analysis showed that the proportion of mutant and wild-type mtDNA of the massive transformant culture, measured after BrdU selection, was the result of the coexistence of two populations of cells, each containing a nearly homoplasmic population of either mutant or wild-type mtDNA. Mitotic segregation has been reported in myoblast clones harboring the $\mathrm{G}^{8344}$ MERRF mutation by Boulet et al. (19). However, in contrast with the latter study, the percentage of the MIMyCa mutation that we detected in the mass transformant culture (56\% mutant mtDNA) differed from that measured in the original muscle biopsy of patient III-1 (90\% mutant mtDNA), suggesting the presence in our cybrid system of negative selection against cells containing the mutation.

The almost absolute mitotic segregation of the two mitochondrial genomes in our transformants suggests the existence of two distinct populations of mitochondria, each containing a homogeneous set of one or the other type of mtDNA (intraorganelle homoplasmy). A minority of mitochondria, containing a mixture of wild-type and mutant genomes (intraorganelle heteroplasmy), could account for the only clone that remained stably heteroplasmic. However, intraorganelle homoplasmy could still be compatible with the coexistence of two populations of mitochondria in the same cell, i.e., interorganelle heteroplasmy.

Therefore, additional mechanisms must be hypothesized to explain the rarity of heteroplasmic clones observed in our study. According to one hypothesis, transformant cybrids could initially be heteroplasmic and could later undergo a rapid selection for either one of the two mitochondrial populations. However, we did not observe any time-dependent variation in the content of the $\mathrm{G}^{\mathbf{3 2 6 0}}$ MIMyCa mutation after selection of the transformants and cell cloning. This result differs from the marked decrease in the content of the wild-type genome reported for both the $G^{3243}$ mitochondrial encephalomyopathy lactic acidosis and strokelike episodes (20) and the $\mathrm{G}^{8344}$ MERRF (19) mutations. Alternatively, transformant cybrids could be produced by myoblasts that are themselves already homoplasmic or nearly homoplasmic for either the mutant or the wild-type genome. As suggested by Boulet et al. (19), since cultured myoblasts derive from muscle satellite cells, i.e., dormant cells that do not replicate after their initial differentiation in the embryo, the mitochondrial segregation observed in the transformants could reflect the original condition of the primordial myogenic cells. To further address this hypothesis, it would be useful to study transformant cybrids derived from cells, such as fibroblasts, that are more heteroplasmic than muscle and that actively proliferate throughout postembryonic life.

Interestingly, the existence of a nearly homoplasmic mutant population of myogenic cells could give rise to areas of the muscle syncytium in which the respiratory capacity is markedly depressed. The regional impairment of OXPHOS could in turn induce, as a compensatory phenomenon, the local proliferation of mitochondria, thus accounting for the ragged-red transformation of discrete areas of muscle fibers.

We have demonstrated that in our cybrid cell system the presence and the amount of the $\mathrm{G}^{3260}$ mutation correlate with defective mitochondrial respiration examined by biochemical analysis of complex I- and complex IV-specific activities, oxygen consumption rate, and lactic acid production. The increase of lactic acid levels is a sensitive index of a block in the aerobic utilization of pyruvate. Oxygen consumption and lactate production were the most discriminating tests between the $M$ and WT groups. This is not surprising since both oxygen consumption and lactic acid production are indexes of the overall aerobic capacity of the cell; if, as in our case, multiple partial defects of the respiratory enzymes are present, their synergistic effect on the aerobic metabolism will result in marked alterations of these indexes. However, both complex I and complex IV were significantly defective as well.

Based on the above considerations and on our experimental results, we conclude that the $A \rightarrow G^{3260}$ mutation is indeed pathogenic and that its presence alone is sufficient to explain the OXPHOS defects found in our MIMyCa patients ex vivo and, presumably, in vivo as well. Our conclusion is further supported by the recent identification of a British kindred harboring $\mathrm{G}^{3260}$ in which several maternal members were affected by MIMyCa of variable severity (21). MIMyCa should therefore be considered a well characterized mitochondrial disease from both clinical and molecular-genetic standpoints.

Since the MIMyCa mutation affects a tRNA gene, it is likely that the molecular pathogenesis leading to the biochemical phenotype consists in the impairment of mitochondrial protein synthesis. This is supported by the demonstration of a generalized defect in mitochondrial translation in a clone nearly homoplasmic for the $\mathrm{G}^{3260}$ mutation.

Although the extent of $\left[{ }^{35} \mathrm{~S}\right]$ methionine incorporation can vary widely among different mutant cell lines and from one experiment to another, it is interesting to note that in the experiment shown in Fig. 1 clone P28 had the lowest $(2.3 \%)$ and clone P8 the highest $(8.7 \%)$ percentages of wild-type $A^{3260}$ in the $\mathrm{M}$ clone group. P28 showed a marked decrease in mitochondrial translation, while P8 showed only a slight decrease, suggesting that under our experimental conditions significant functional complementation for mitochondrial protein translation can occur in the presence of $<10 \%$ wild-type genome. This is in agreement with studies carried out in myoblast clones harboring the $\mathrm{G}^{8344}$ MERRF mutation, which demonstrated that mitochondrial translation and complex IV activity were restored to near normal levels in the presence of an amount of wild-type mtDNA as low as $15-16 \%$. However, the rise in incorporation of $\left[{ }^{35} \mathrm{~S}\right]$ methionine in P28 after $60 \mathrm{~min}$ of labeling suggests the presence of a defect in the rate of translation rather than in the steady state levels of mitochondrial protein synthesis. It is possible that shorter pulses of labeling may disclose a defect in incorporation also in clones with lower amounts of mutant $\mathrm{G}^{3260}$. 


\section{Acknowledgments}

We thank Dr. Michael King and Dr. Anu Suomalainen for useful advice and discussion.

This work was supported in part by Telethon-Italy (grant to $\mathbf{M}$. Zeviani) and Associazione Italiana per la promozione delle Ricerche Neurologiche.

\section{References}

1. Zeviani, M., C. Gellera, C. Antozzi, M. Rimoldi, L. Morandi, F. Villani, V. Tiranti, and S. DiDonato. 1991. Maternally inherited myopathy and cardiomyopathy: association with mutation in mitochondrial DNA tRNA Leu(UUR). Lancet. 338:143-147.

2. Anderson, S., A. T. Bankier, B. G. Barrell, M. H. L. de Bruijn, A. R. Coulson, J. Drouin, I. C. Eperon, D. P. Nierlich, B. A. Roe, F. Sanger, et al. 1981. Sequence and organization of the human mitochondrial genome. Nature (Lond.). 290:457-465.

3. King, M., and G. Attardi. 1989. Human cells lacking mitochondrial DNA: repopulation with exogenous mitochondria by complementation. Science (Wash. DC). 246:500-503.

4. Suomalainen, A., P. Kollmann, J. N. Octave, H. Söderlund, and A. C. Syvänen. 1993. Quantification of mitochondrial DNA carrying the $\operatorname{tRNA}_{8344} \mathrm{Ly}_{\mathrm{s}}$ point mutation in myoclonus epilepsy and ragged-red fiber disease. Eur. J. Hum. Genet. 1:88-95.

5. Askanas, V., and W. K. Engel. 1975. New program for investigating adult human skeletal muscle grown aneurally in tissue culture. Neurology. 25:58-67.

6. Zeviani, M., T. Moraes, S. DiMauro, H. Nakase, E. Bonilla, E. A. Schon, and L. P. Rowland. 1988. Deletions of mitochondrial DNA in Kearns-Sayre syndrome. Neurology. 38:1339-1346.

7. King, M., Y. Koga, M. Davidson, and E. A. Schon. 1992. Defects in mitochondrial protein synthesis and respiratory chain activity segregate with the tRNA ${ }^{\text {Leu(UUR) }}$ mutation associated with mitochondrial myopathy, encephalopathy, lactic acidosis, and strokelike episodes. Mol. Cell. Biol. 12:480-490.

8. Eubanks, J. H., L. Selleri, R. Hart, C. Rosette, and G. A. Evans. 1991. Isolation, localization, and physical mapping of a highly polymorphic locus on human chromosome 11q13. Genomics. 11:720-729.

9. Chomyn, A., G. Meola, N. Bresolin, S. T. Lai, G. Scarlato, and G. Attardi.

1991. In vitro genetic transfer of protein synthesis and respiration defects to mitochondrial DNA-less cells with myopathy-patient mitochondria. $\mathrm{Mol}$. Cell. Biol. 11:2236-2244.

10. Lowry, O. H., N. J. Rosebrough, A. L. Farr, and R. J. Randall. 1951 Protein measurement with the Folin phenol reagent. J. Biol. Chem. 193:265275.

11. Laemmli, U. K. 1970. Cleavage of structural proteins during assembly of the head of bacteriophage $T_{4}$. Nature (Lond.). 227:680-685.

12. Darley-Usmar, V. M., D. Rickwood, and M. T. Wilson, editors. 1987. Mitochondria, A Practical Approach. IRL Press, Oxford/Wash. DC. 321 pp.

13. Noll, F. 1974. Determination with LDH, GPT and NAD. In Methods of Enzymatic Analysis. Vol. 3. H. U. Bergmeyer, editor. Verlag Chemie, Weinheim; Academic Press Inc., New York. 1475-1479.

14. Wallace, D. C., M. T. Lott, A. Torroni, and J. M. Shoffner. 1991. Report of the committee on human mitochondrial DNA. Cytogenet. Cell Genet. 58:1103-1123.

15. Marzuki, S., S. A. Noer, P. Lertrit, D. Thyagarajan, R. M. I. Kapsa, P. Utthanaphol, and E. Byrne. 1991. Normal variants of human mitochondrial DNA and translation products: the building of a reference data base. Hum. Genet. 88:139-145.

16. Howell, N., D. A. McCullogh, I. Kubacka, S. Halvorson, and D. Mackey. 1992. The sequence of human mtDNA: the question of errors versus polymorphisms. Am. J. Hum. Genet. 50:1333-1337.

17. Marzuki, S., P. Lertrit, S. A. Noer, R. M. I. Kapsa, H. Sudoyo, E. Byrne, and D. Thyagarajan. 1992. The need for a joint effort in the construction of a reference data base for normal sequence variants of human mtDNA. Am. J. Hum. Genet. 50:1337-1340.

18. Shoffner, J. M., M. T. Lott, A. M. S. Lezza, P. Seibel, S. W. Ballinger, and D. C. Wallace. 1990. Myoclonic epilepsy and ragged-red fibers disease (MERRF) is associated with a mitochondrial DNA tRNA ${ }^{\text {lys }}$ mutation. Cell. 61:931-937.

19. Boulet, L., G. Karpati, and E. A. Shoubridge. 1992. Distribution and threshold expression of the trans-RNA(Lys) mutation in skeletal muscle of patients with myoclonic epilepsy and ragged-red fibers (MERRF). Am. J. Hum. Genet. 51:1187-1200.

20. Yoneda, M., A. Chomyn, A. Martinuzzi, O. Hurko, and G. Attardi. 1992. Marked replicative advantage of human mtDNA carrying a point mutation that causes the MELAS encephalomyopathy. Proc. Natl. Acad. Sci. USA. 89:1116411168.

21. Sweeney, M. G., M. Brockington, M. J. Weston, J. A. MorganHughes, and A. E. Harding. 1993. Mitochondrial DNA transfer RNA mutation Leu(UUR)A $\rightarrow$ G 3260 : a second family with myopathy and cardiomyopathy. Ann. Med. In press. 